\title{
Knowledge, Attitude And Expectation of Mothers of Children With Neurologic Disorders Attending The Paediatric Neurology Clinic, University Of Benin Teaching Hospital, Benin City, Nigeria.
}

\author{
${ }^{1}$ G. E. OFOVWE, ${ }^{2}$ C. E. OFOVWE
}

\begin{abstract}
Background: The high rate of default from follow up clinic by children with chronic neurological disorders and shopping around from one place to another in search of a cure by their mothers may be as a result of ignorance concerning the diagnosis, cause and prognosis of these disorders. The ignorance of mothers may be as result of lack of adequate information from medical personnel at time of initial consultation.

Objectives: To assess mothers whose children were referred to the paediatric neurology clinic to determine what they know and feel about the cause, management, prognosis and their expectation regarding the disorders.

Study design and methods: The study was conducted between January 7th 2004 and December 8th 2004 in the paediatric neurology clinic of University of Benin Teaching Hospital, Benin City, Nigeria using a semi-structured questionnaire. Responses were aggregated and expressed as simple percentages and analyzed using SPSS 10.0 for windows.

Results: One hundred and ten mothers aged between 21 and 65 years were recruited. 21.8\%, $19.1 \%$ and $23.6 \%$ knew the cause, diagnosis and outcome respectively while $30 \%$ had diagnosis explained. Over $70 \%$ of the mothers had negative attitude toward their children being seen in public. All the mothers expected cure while $98.2 \%$ were willing to share their experience with other mothers.

Conclusion: Majority of the mothers lack adequate information about possible cause, diagnosis and outcome of their children's neurological disorder at referral. Willingness of almost all mothers to share experience with others provides opportunity for group therapy and formation of support groups.
\end{abstract}

\section{INTRODUCTION}

Neurological disorders in children are common occurrence in clinical practice. A lot

KEYWORDS: Knowledge, Attitude, Expectation, Mothers, Children, Neurological Disorders

${ }^{1}$ Department of Child Health, ${ }^{2}$ Department of Mental Health, School of Medicine, College of Medical Sciences, University of Benin, Benin City, Nigeria.

Correspondence: Dr. Gabriel E. Ofovwe, Department of Child Health, University of Benin, P. M. B. 1154, Benin City, Nigeria. E-mail:gofo@childhealthuniben.com of these disorders are chronic, frustrating to caregivers and parents and require adequate understanding to cope with management. Empirical observation suggest that the general attitude of parents of children with chronic illnesses such as neurological disorders in developing countries such as Nigeria is to shop from one doctor to another in search of a cure or solution 
leading to a "fat file syndrome" and high rate of default from follow-up. ${ }^{1}$ One factor which appears to contribute to this attitude is ignorance of the parents concerning causes, management and prognosis of these disorders in their children., ${ }^{1,2}$ The reason for this ignorance is partly because adequate information is not given to them during consultation with medical personnel ${ }^{3}$. In Nigeria there appears to be paucity of studies on the type and depth of information given to parents of children with chronic illness to empower them toward achieving adequate coping strategies, informed decision making and participation in the management of their children. We therefore decided to assess mothers whose children were referred to the paediatric neurology clinic of the University of Benin Teaching Hospital, Nigeria to determine what they know and feel about the cause, prognosis and their expectation.

\section{METHODS}

This study was done in the paediatric neurology clinic of the Department of Child Health, University of Benin Teaching Hospital (UBTH) Benin City, Edo State. UBTH is a 500 bed tertiary centre of referral which serves Edo State and contiguous States such as Delta, Ondo and Kogi in the South, West and Southwestern region of Nigeria. The Child neurology clinic runs weekly on Wednesdays from 8 am to $2 \mathrm{pm}$. An Average of 23 old and 5 new cases are seen on each clinic day. Mothers of children referred to the clinic between January 7th 2004 and December 8th 2004 were assessed at first visit after informed consent using a semi-structured questionnaire developed by the authors. Parameters assessed included: - Age and educational level of mothers, age of the child at presentation, knowledge of the cause, diagnosis, and outcome of the neurological problem and source of information. If they had any explanation of the diagnosis and from whom it was gotten, how they feel about the child being seen in public and willingness to share their experiences with other parents with similar problems. The questionnaires were administered and retrieved after completion within a few minutes in the presence of one of the authors (GEO) assisted by resident doctors rotating through the neurology unit. Mothers who could not read had the questionnaire explained and their response entered by the interviewer. Participation was voluntary. Responses were aggregated and recorded as simple percentages. Analysis was done with SPSS 10.0 for windows. Chi square statistic was used to test the significance of differences between proportions.

\section{RESULTS}

A total of 110 mothers aged between 21 and 65 years were recruited. The mean \pm S.E.M age of the mothers was 33.97 years \pm 0.81 . Table 1 shows the sociodemographic characteristics of the mothers. Of the 110 mothers studied 42 (38.3\%) were referred to the neurology clinic by doctors in private practice while 68 (61.8\%) were self referrals to the General Practice Clinic (GPC) of UBTH where they were first evaluated and then subsequently referred by doctors to the paediatric neurology clinic. Table 2 shows the knowledge, attitude and expectations of the mothers concerning the neurological disorders of their children at first visit. 4 $(15.4 \%)$ of the 26 mothers with primary education knew the cause of their children's neurologic disorder compared to $10(17.9 \%)$ of 56 mothers with secondary and 10 (35.7\%) of mothers with tertiary education respectively. There was no significant association between mothers education and knowledge of the cause of their children's neurologic disorders $\left(x^{2}=4.37 ; \mathrm{df}=2 ; \mathrm{P}>\right.$ 0.05). Concerning knowledge of the diagnosis, education was found to be significantly associated with knowledge of the diagnosis as $12 / 28$ (42.9\%) of mothers 
with tertiary education knew the neurologic diagnosis of their children's illness compared to $4 / 26(15.4 \%)$ mothers with primary and $5 / 56$ (8.6\%) with secondary education respectively $\left(\chi_{\mathrm{y}}{ }^{2}=14.21 ; \mathrm{df}=2 ; \mathrm{P}<0.001\right)$. There was no significant association between source of referral of mothers and their knowledge of cause of their children's neurologic disorders. 12/42 (28.6\%) mothers who were referred by private doctor knew the cause of their children's neurologic disorder compared to $12 / 68(17.6 \%)$ referred by self/GPC $\left(\chi^{2}=1.82 ; \mathrm{df}=1 ; \mathrm{P}>0.05\right)$. Likewise no significant association was found between source of referral and knowledge of diagnosis. 9/42 (21.4\%) mothers referred by private doctors knew the diagnosis of the children compared to $12 / 68(17.6 \%)$ referred by self/GPC $\left(\chi^{2}=0.24 ; \mathrm{df}=1 ; \mathrm{P}>0.05\right) .12 / 24$
(50\%) of the mothers who knew the cause of the problem of their children had the diagnosis explained to them compared to 21/86 (24.4\%) of mothers who did not know but had diagnosis explained to them. There was a significant association between mothers' knowledge of the cause of their children's problem and explanation of the diagnosis to them $\left(\chi^{2}=5.847 ; \mathrm{df}=1 ; \mathrm{P}<\right.$ 0.05). Similarly $13 / 21$ (61.9\%) of the mothers who knew the diagnosis of their children's neurological problem had the diagnosis explained to them while 20/89 (22.5\%) of mothers who did not know had explanation of the diagnosis. There was a significant difference between these proportions $\left(\chi^{2}=\right.$ 12.581; df $=1 ; \mathrm{P}<0.001)$. All the mothers evaluated expected a cure based on one belief or the other summarized in table 3.

Tables 1. Sociodemographic characteristics of the mothers.

$\mathrm{n} \quad \%$

$\underline{\text { Marital Status }}$

Married

Single

Educational Level

Primary

Secondary 
62 Journal of Medicine and Biomedical Research

Table 2. Knowledge, attitude and expectations of mothers concerning the neurological disorder of their children.

\begin{tabular}{lll}
\hline & $\mathrm{n}$ & $\%$ \\
\hline Know Cause & 24 & 21.8 \\
Know Diagnosis & 21 & 19.3 \\
Know outcome & 26 & 23.6 \\
Diagnosis Explained & 33 & 30.0 \\
Mother's feeling when child seen in public & & \\
$\quad$ Indifferent & 26 & 23.6 \\
$\quad$ Unhappy/Ashamed/Embarrassed & 84 & 76.4 \\
Mother's feeling when bringing child to the clinic & & 10.0 \\
$\quad$ Hopeful & 11 & 18.2 \\
$\quad$ Indifferent & 20 & 71.8 \\
$\quad$ Unhappy/Ashamed & 79 & 100.0 \\
Expecting Cure & 110 & 98.2 \\
\hline Willing to share Experience & 108 & \\
\hline
\end{tabular}

Table 3: Reasons given for expecting a cure by mothers.

\begin{tabular}{lll}
\hline & $\mathrm{n}$ & $\%$ \\
\hline Illness in Curable & 6 & 5.4 \\
Divine Intervention & 52 & 47.3 \\
Don't know & 23 & 20.9 \\
Faith in the doctors & 29 & 26.4 \\
\hline Total & 110 & 100.0 \\
\hline
\end{tabular}




\section{DISCUSSION}

In this era when adequate information about disease processes is being emphasized as an important factor in patient satisfaction, a means of enhancing quality of health care ${ }^{3-10}$ and a prerequisite for the development of optimal coping strategy and informed decision making, ${ }^{13}$ less than $24 \%$ of mothers in this study knew the cause, diagnosis and prognosis of their children's neurological disorder at referral. Similar findings have been reported by other workers. ${ }^{5,12,15}$ The implication of lack of adequate information to mothers of children with neurological disorders especially in developing countries like Nigeria is that of unattainable expectation such as cure for permanent brain damage. When expectation of cure is not met within a short time, mothers become dissatisfied, frustrated and subsequently default from follow up $^{1}$ and sometimes sort help from non medical sources such as churches and traditional healer/charlatans ${ }^{2}$. A major consequence is development of negative attitudes such as unhappiness, shame and embarrassment when people see their children in public. Negative attitude as expressed in this study by majority of mothers also contribute to high default rate in developing countries. Furthermore because of the lack of personnel and facilities for rehabilitation needed for children with these chronic and disabling neurological disorders in developing countries their mothers or primary care givers are often required to play important role in the management at home. In the light of this, knowledge about the cause, course and prognosis becomes very important for the mothers to make adequate adjustment in time. ${ }^{13}$ Lack of adequate communication particularly as it pertains to provision of information from doctors to parents/patients about disease processes is not peculiar to developing countries, sadly, it seems a wide spread problem. ${ }^{3,5,12-15}$ This problem may be due to peculiarity of the medical training. Often, emphasis on ability to elicit good history in clinical methods for diagnostic purposes is stressed to the near neglect of conveying clear and adequate information. The ability to convey adequate information to patients is thus left to the doctors' idiosyncratic experience and practice. No doubt, this calls for improvement as the need for adequate information is of utmost importance in health care delivery. ${ }^{3}$ The finding of significant association between explanation of diagnosis to mothers and their knowledge of the cause and diagnosis of neurological disorders of their children underscores the importance of the need for doctors to patiently and clearly explain issues of diagnosis to mothers of sick children. The significant association found between mothers' educational level and knowledge of the diagnosis of their children's neurological disorder emphasis the role of education as a necessary tool of enlightenment. It also shows that the more educated a mother is the more likely she will ask the doctor about the illness affecting her child.

The expression of willingness to share their experience by $98 \%$ of mothers creates an important avenue for group therapy with potential to reduce the burden of chronic and permanent neurological disorders on mothers and caregivers by facilitating development of coping strategy. Group therapy is not a known modality in the management of chronic or disabling neurological disorders such as epilepsy and cerebral palsy in Nigeria either because the need for it has not been previously emphasized or its importance underplayed. However the benefits of group therapy can not be over emphasized as it would provide a forum for mothers to express and share their experiences, frustrations and hope with one another and the healthcare team. ${ }^{13}$ This will also help the healthcare team to appreciate the needs of the mothers and children for a 
holistic approach to management of the family.

It is surprising to note that all the mothers in this study expected cure for their children's neurological disorder irrespective of the nature and diagnosis. This expectation is borne out of ignorance and cultural /religious believes which are re-enforced by the unregulated activities of traditional medicine practitioners and other charlatans on print and electronic media in Nigeria. ${ }^{2}$ This may also explain why majority of mothers (47.3\%) cutting across all educational levels based their expectation of cure on divine intervention.

In conclusion majority of the mothers lack adequate information about possible cause, diagnosis and outcome of their children's neurological disorder at referral due to inadequate information which often results in unattainable expectation such as cure for permanent brain damage and negative attitude as exemplified by the feeling of shame, unhappiness, embarrassment in public and default from follow up clinics. It is recommended that physicians should endeavour to explain in adequate and clear terms possible causes, nature and outcome of diseases to patients and mothers and this should be emphasized in the training of doctors at the undergraduate level. Finally group therapy among mothers should be encouraged in the management of children with chronic and disabling neurological disorders, as this will lighten their burden, ensure adequate coping measures and compliance with therapy.

\section{ACKNOWLEDGEMENTS}

We are grateful to the mothers who participated in this study for their patients and understanding. We also acknowledge with gratitude the doctors who assisted in administration and collection of the questionnaire.

\section{References.}

1. Izoura GI, Iloeje SO. A review of neurological disorders seen at the Paediatric Neurology Clinic of the University of Nigeria Teaching Hospital, Enugu. West Afr J Med. 1993; 12(1):1-5.

2. Ofovwe GE, Ibadin MO, Ofovwe C E , Okolo AA. Home management of febrile convulsions in an African population: a comparison of urban and rural mother's knowledge, attitude and practice. J Neurol Sci; 2002; 200 (1 2): 49-52.

3. Hishan B. Customer satisfaction, $\mathrm{t}$ h e patients point of view. Med Abstr 2000; 3; 5-6

4. Miller NB. Parents of Children with Neurological Disorders: Concerns and Counseling. Journal of Pediatric Psychology 1979; 4(3); 297 306

5. Ofovwe CE, Ofili AN. Indices of patient satisfaction in an African population. Public Health 2005; 119; 582-6

6. Fitzpatrick R. Surveys of patient satisfaction: Important general considerations. Br Med J 1991; 302: 887 - 9

7. Anja T, Marjo-Riitta J, Jorma K. Parental guidance and counselling by doctors and nursing staff: parents' views of initial information and advice for families with disabled children. Journal of clinical Nursing. 1998; 7; (6); 505 - 11 
8. Mendoza AJ, Piechulek H, al Sabir A, Client satisfaction and quality of health care in rural Bangladesh. Bull World Health Organ. 2001; 79:512 17

9. Sigh H, Hagy E, Mustafa M. Patients perception and satisfaction with health care professionals in primary care facilities in Trinidad and Tobago. Bull wld hlth Org. 1999; 77: 356-60

10. Perreault M, Liechner P, Sabourin S, Gendreau P. Patient satisfaction with outpatient psychiatic services; qualitative and quantitative assessments. Eval Program Plann 1993; 16: 109 -18

11. Kristensson-Hallstrom I, Nilstun T. The parent between the child and the professional some ethical implications. Child Care Health Dev. 1997 Nov; 23(6):447-55
12. Brewster S, Jarman B,Bosaquet $M$. National survey of hospital patients. $\mathrm{Br}$ Med J. 1994; 309: 1542 - 6

13. Rahi JS, Monaras I, Tuomainen H, Hundt GL. Meeting the needs of parents around the time of diagnosis of disability among their children: evaluation a novel program for information, support and liaison by key workers. Paediatrics. 2004; 114(4):477-82

14. Starke M, Moller A.Parents' need for knowledge concerning the medical diagnosis of their children. J Child Health Care. 2002; 6(4):245-57

15. Rahi JS, Monaras I, Tuomainen H, Hundt GL. Health services experiences of parents of recently diagnosed visually impaired children. $\mathrm{Br} \mathrm{J}$ Ophthalmol. 2005; 89(2):213-8 